\section{(6) OPEN ACCESS}

\title{
Acceptability of different oral formulations in infants and preschool children
}

\author{
Diana A van Riet-Nales, ${ }^{1,2}$ Barbara J de Neef, ${ }^{3}$ Alfred F A M Schobben, ${ }^{2}$ \\ José A Ferreira, ${ }^{4}$ Toine C G Egberts, ${ }^{2,5}$ Catharine M A Rademaker ${ }^{5}$
}

\begin{abstract}
${ }^{1}$ Medicines Evaluation Board in the Netherlands, Department of Chemical Pharmaceutical Assessment, Utrecht, The Netherlands (until 2011 this department belonged to the National Institute of Public Health and the Environment) ${ }^{2}$ Utrecht University, Faculty of Science, Utrecht Institute for Pharmaceutical Sciences, Department of

Pharmacoepidemiology and Clinical Pharmacology, Utrecht,

The Netherlands

${ }^{3}$ Stichting Thuiszorg en

Maatschappelijk Werk

Rivierenland, Sector Child care, Tiel, The Netherlands

${ }^{4}$ National Institute for Public Health and the Environment, Department of Statistics, Modelling and Data Management, Bilthoven, The Netherlands

${ }^{5}$ University Medical Centre Utrecht, Department of Clinical Pharmacy, Utrecht, The Netherlands
\end{abstract}

\section{Correspondence to} Diana A van Riet-Nales, Medicines Evaluation Board, Department of Chemical Pharmaceutical Assessment (CFB), Graadt van Roggenweg 500, P.O. Box 8275, Utrecht 3503 RG, The Netherlands; da.v.riet@cbg-meb.nl

Received 30 October 2012 Revised 25 May 2013 Accepted 28 May 2013 Published Online First 13 July 2013

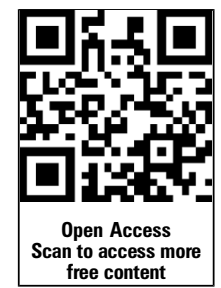

\begin{tabular}{l}
\hline To cite: van Riet-Nales DA, \\
de Neef BJ, \\
Schobben AFAM, et al. Arch \\
Dis Child 2013;98: \\
725-731. \\
\hline
\end{tabular}

\section{ABSTRACT}

Objective Liquid medicines are easy to swallow.

However, they may have disadvantages, such as a bad taste or refrigerated storage conditions. These disadvantages may be avoided by the use of oral solid medicines, such as powders or tablets. The aim of this study was to investigate the acceptability of and preference among four oral formulations in domiciliary infants and preschool children in The Netherlands. Methods Parents administered four oral placebo dosage forms that were aimed at a neutral taste, at home, to their child (1-4 years of age) twice on one day following a randomised cross-over design: small $(4 \mathrm{~mm})$ tablet, powder, suspension and syrup. They were asked to report the child's acceptability by a score on a $10 \mathrm{~cm}$ visual analogue scale (VAS score) and by the result of the intake. At the end of the study, they were asked to report the preference of the child and themselves.

Results 183 children were included and 148 children were evaluated. The data revealed a period/cross-over effect. The estimate of the mean VAS score was significantly higher for the tablet than for the suspension (tablet 9.39/9.01; powder 8.84/8.20, suspension 8.26/ 7.90 , syrup $8.35 / 8.19$; data day $1 /$ all days). The estimate of the mean number of intakes fully swallowed was significantly higher for the tablet than for the other formulations (all $p$ values $<0.05$ ). Children and parents preferred the tablet and syrup over the suspension and the suspension over the powder (all $p$ values $<0.05$ ).

Conclusions All formulations were well accepted. The tablets were the best accepted formulation; the tablets and syrup the most preferred.

Trial Registration number ISRCTN63138435.

\section{INTRODUCTION}

For decades, oral liquid dosage forms, such as syrups and suspensions, have been considered as the favourable type of dosage form in which to administer medicines to young children. ${ }^{1}{ }^{2}$ However, oral liquid medicines may have disadvantages, such as a bad taste, portability problems or refrigerated storage conditions. ${ }^{3-6}$ Therefore, WHO currently favours that young children, particularly in developing countries, be treated with oral solid medicines. ${ }^{7}$

Oral liquid medicines are more commonly available for use in infants and preschool children than oral solid (flexible) medicines, such as powders or orodispersible tablets. ${ }^{8}$ Small-sized tablets, also referred to as minitablets, have been identified as a new type of oral solid dosage form in which to administer medicines to young children. However, only few of such tablets have been authorised for children below 4 years of age. ${ }^{3}{ }^{9-11}$ Nevertheless,

\section{What is already known on this subject}

- Oral medicines are frequently administered to infants and preschool children as a liquid formulation.

- Liquid formulations may have disadvantages, such as a bad taste or refrigerated storage conditions.

- Small tablets can be used to administer medicines to young children.

\section{What this study adds}

- Minitablets (4 $\mathrm{mm}$ diameter) were the most acceptable formulation to healthy Dutch infants and preschool children.

- Both parents and children preferred the minitablets and syrups to the suspensions and powders.

small tablets have been widely used in this age group as food supplements, for example, $4 \mathrm{~mm}$ sodium fluoride tablets for caries prevention, or 4 $\mathrm{mm}$ vitamin $\mathrm{AD}$ tablets. ${ }^{12-16}$

The selection of an oral dosage form and the pharmaceutical aspects of the formulation, such as the palatability of an oral suspension or the size of a tablet, are important factors in the overall acceptability of an oral paediatric medicine. ${ }^{6}{ }^{10}$ As adequate child and parent acceptability are prerequisites for good drug adherence, paediatric treatment outcomes may be enhanced by a careful selection of the formulation including the type of the dosage form. Therefore, the aim of this study was to investigate the acceptability of and preference among four oral formulations in domiciliary, infants and preschool children in The Netherlands.

\section{METHODS}

\section{Study design}

A randomised cross-over trial was performed in six Dutch preschool preventive healthcare clinics in Beusichem, Beesd, Culemborg (2 clinics), Maurik and Zaltbommel. Ethical approval was waived by the Central Committee on Research involving human subjects (CCMO) on basis of the Dutch Medical Research Involving Human Subjects Act (WMO). Approval was obtained from the 
Institutional Review Board of the Utrecht Institute for Pharmaceutical Sciences (UIPS).

\section{Setting and study participation}

The aim of the preschool preventive healthcare clinics is to monitor the mental and physical development of children between 0 and 4 years of age, to advise parents on child-raising issues and to vaccinate children. ${ }^{17}$ The response rate to the invitation for an appointment is over $99 \%$ of children below 2 years of age and over $90 \%$ of children between 2 and 4 years of age. ${ }^{18}$

Parents were verbally approached by one of four recruiters (a licensed pharmacist and three graduate students) when attending the clinics in 2011. Parents had either received the written information by mail 2 weeks before the appointment, or this information was handed to them at the end of the face-to-face contact. Parents were asked or called by phone for written informed consent and study participation at least 2 weeks after the written information was provided. The results of the selection process were systematically gathered (date when verbally approached, healthcare clinic, recruiter, date of birth, child gender, willingness to participate, reason for exclusion if mentioned voluntarily).

Children were eligible for inclusion in this study if they were between 1 and 4 years of age and if their parents had mastery of the Dutch language. Exclusion criteria were: (1) significant developmental delay; (2) having swallowing difficulties, an eating disorder or a chronic condition requiring oral medication; (3) hypersensitive to lactose, having cow-milk allergy or having an allergy of unknown origin; (4) a member of staff of the preventive healthcare clinic considered that study participation was inappropriate in view of the family situation. During the study, the criterion added was (5) according to the parents' observation, children should not feel ill when the formulations were actually given.

\section{Intervention}

Parents were asked to administer four oral placebo formulations to their child at home during normal family routines. They were asked to administer the formulations (4 mm tablet, powder, suspension and syrup) in the same way they would administer a prescribed medicine, however, without any physical or physiological pressure (table 1). In conformity with common Dutch dispensing procedures for immediate release formulations, chewing and coadministration/mixing with food or drinks was neither recommended nor forbidden. Parents were instructed to administer the formulations on four consecutive days; however, they were allowed to skip a day if necessary. In order to study any period or carry-over effect, the formulations should be given in a predefined, randomised order, and each formulation twice on 1 day only. The formulations were specifically developed and manufactured for this study by ACE Pharmaceuticals, The Netherlands.

\section{Outcomes}

Acceptability after each administration: (1) visual analogue scale (VAS) score for child acceptability according to the parents' observation (0-10 cm VAS scale; from 0 'heel erg vervelend' (very unpleasant/bothersome etc), to 10 'helemaal niet vervelend' (not at all unpleasant/bothersome etc) and (2) result of the intake according to the parents' observation (full dose swallowed, parts of the dose swallowed, dose not swallowed). If parents indicated that they had forgotten to administer the formulation to the child, then the absent VAS scores and absent values for the result of the intake were considered 'missing values'. If parents indicated that they had not administered the formulation to the child for any other reason, then the absent VAS scores were set at ' 0 ' and the absent results of the intake at 'not swallowed'.

Preference at the end of the study: (1) the single most preferred formulation of the child according to the parents' observation; (2) the single most preferred formulation of the parents for the child.

Others: Questions concerning other family characteristics and the exact manner the formulations were administered to the child.

\section{Sample size}

The sample size for acceptability was calculated on basis of a design aimed at detecting a specified difference between the VAS scores of two treatments in a cross-over trial involving four oral formulations on four different days. ${ }^{19}$ The power was set at 0.8 and the significance level at 0.05 . Due to a lack of relevant data from the literature on the acceptability of oral formulations in (young) children, the sample size calculations were based on plausible values for the mean difference and SD of the VAS scores. The sample size for preference was calculated on basis of a statistical design where parents were asked to identify the single most preferred formulation. The same approach was applied as for the calculation of the acceptability. The sample size was set at 150 evaluable children, which would, in most cases, allow a maximum difference of 2 for acceptability and 0.2 for preference to be detected.

\section{Randomisation}

The study was randomised for the order of administration of the formulations by an RIVM employee who was not involved in this study. Randomisation was conducted with a random sequence obtained from http://www.random.org. The same sequence was applied to each block of 24 children. Siblings were allocated to the same order to avoid mistakes.

\section{Data analysis}

The following analyses were conducted: (1) assessment of systematic differences between the two single VAS scores for a particular formulation (paired $Z$ tests); (2) in case of no significant differences, calculation of the mean VAS scores per child and formulation; (3) evaluation of a potential cross-over or period effect ( $Z$ test on the order of the best accepted formulation), in case of such an effect analysis 3 and 4 were done for the administrations of the first formulation only (day 1) and for all data (all 4 days); (4) estimation of the mean VAS score per formulation and computation of the corresponding 95\% CIs ( $\mathrm{Z}$ statistics); (5) testing of differences between the mean VAS scores of two different formulations (Wilcoxon and Mann-Whitney tests); (6) estimation of the mean number of intakes that were fully swallowed by a child per formulation and computation of the corresponding 95\% CIs ( $Z$ statistics); (7) computation of estimates and associated 95\% CIs of the probabilities that the child and parents preferred a particular formulation, and comparison between the four probabilities ( $\mathrm{Z}$ tests).

All statistics were conducted applying Excel 2007 (Microsoft, Redmond, Washington), R V.2.13 (R development core team).

\section{RESULTS}

Setting and study participation

Between February and July 2011, 421 children from 373 families were verbally approached; 405 children from 358 families 


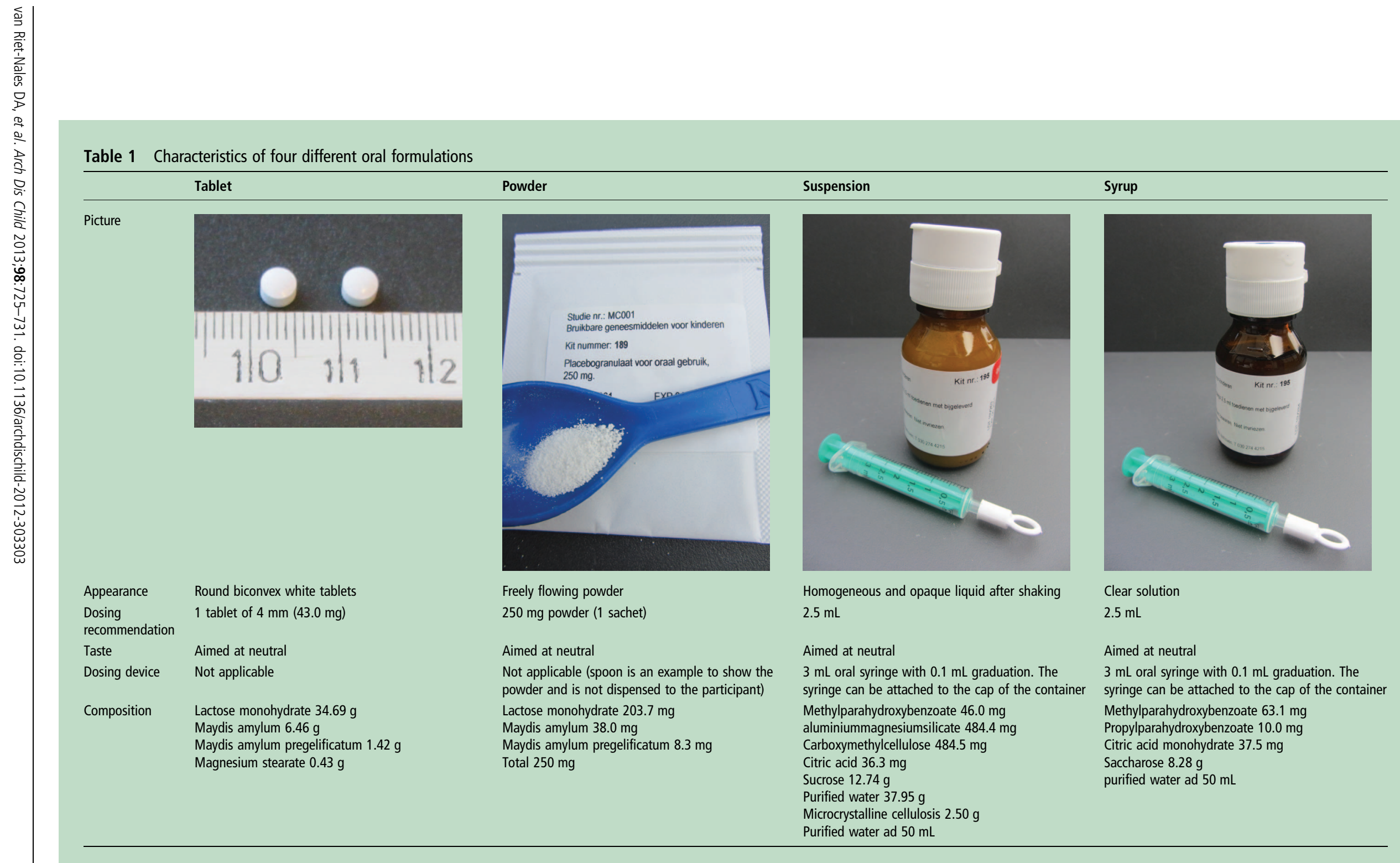

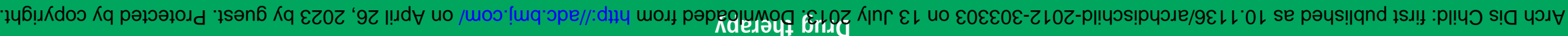


were eligible for inclusion if their parents would pass the language check. Informed consent was obtained for 183 children from 153 families. Diaries including information on the acceptability and preference of the formulations were returned for 151 children from 124 families (recruitment success rate $45 \%$, loss to follow-up 17\%). Three diaries from two families could not be used in the data analysis because it was not clear in which order the formulations were administered (figures 1 and 2). The recruitment success rate in the population eligible for inclusion was similar among all the participating healthcare

\begin{tabular}{|c|c|}
\hline $\begin{array}{l}\text { verbally approached by one of four } \\
\text { recruiters } \\
n=421 \text { children (aged } 1-4 \text { yrs) } \\
n=373 \text { families }\end{array}$ & $\begin{array}{l}\text { not approached on indication preventive } \\
\text { health care clinic } \\
\mathrm{n}=3 \text { children } \\
\mathrm{n}=1 \text { family }\end{array}$ \\
\hline
\end{tabular}

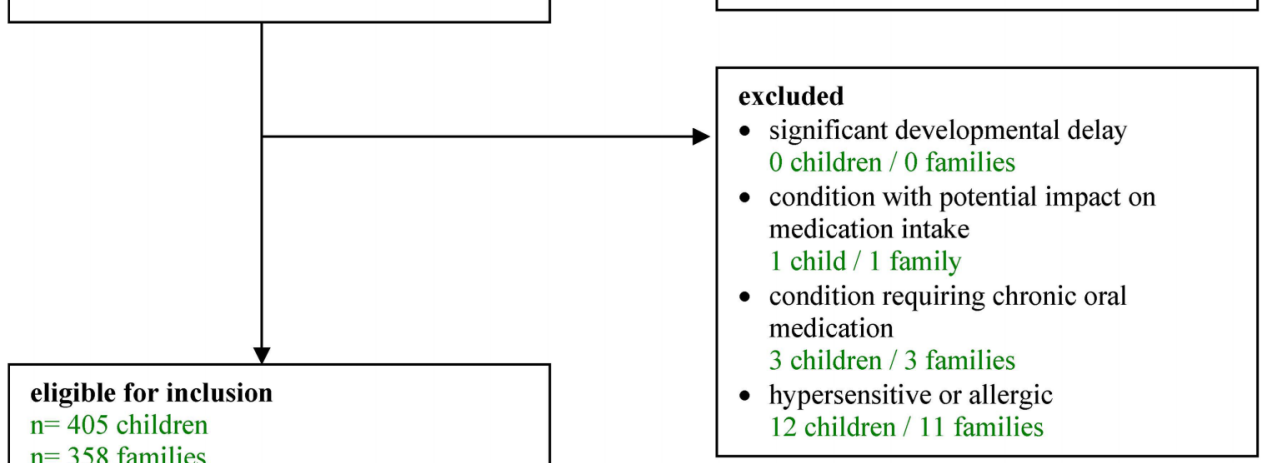

$$
\begin{aligned}
& n=405 \text { children } \\
& n=358 \text { families }
\end{aligned}
$$

unwilling to participate and/or

insufficiënt mastery of the NL language

and/or no final decision obtained

$\mathrm{n}=222$ children

willing to participate and positive

$\mathrm{n}=205$ families

\section{language check \\ $\mathrm{n}=183$ children \\ $\mathrm{n}=153$ families}

diaries lacking acceptability/preference

data

- father withdrew informed consent

$\mathrm{n}=1$ child

$\mathrm{n}=1$ family

- child got ill / started oral medication $\mathrm{n}=4$ children

$\mathrm{n}=3$ families

\section{letter or call from parents}

- parents had no time

$n=5$ children

$\mathrm{n}=4$ families

- study was interruped (child refusal)

$\mathrm{n}=1$ child

$\mathrm{n}=1$ family

- child got ill / started oral medication $\mathrm{n}=4$ children

$\mathrm{n}=4$ families

no feedback from parents

$n=17$ children

returned diaries

$\mathrm{n}=151$ children ( 75 boys, 76 girls)

$\mathrm{n}=124$ families

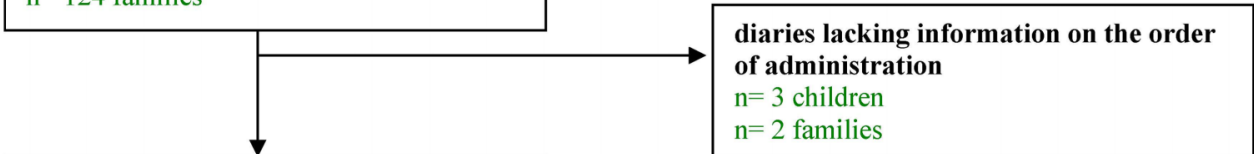

returned diaries suitable for evaluation

$\mathrm{n}=148$ children ( 74 boys, 74 girls)

$\mathrm{n}=122$ families

Figure 1 Participant flow through the study. 
Figure 2 Visual analogue scale to report the child acceptability example shown for the powder.

\section{Hoe vervelend vond uw kind het om het poeder in te nemen? Zet een streepje op de lijn}

\begin{tabular}{|c|c|c|}
\hline & 2 & 3 \\
\hline
\end{tabular}

heel erg vervelend een beetje vervelend

helemaal niet vervelend

\section{English translation \\ How unpleasant was the powder for your child? Put a mark on the line}

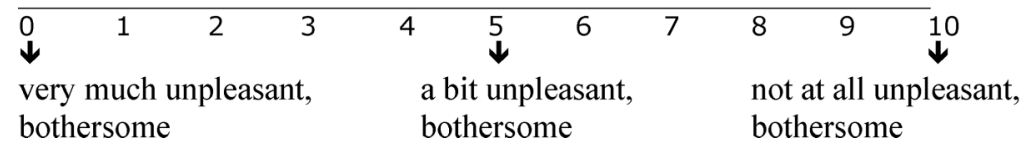

clinics and recruiters. The age and gender of the children eligible for evaluation were not statistically different from the children eligible for inclusion.

\section{Child and parent acceptability}

The data did not indicate systematic differences between the single VAS scores of the two administrations of each formulation to a child. Therefore, the mean VAS scores were used for the further evaluations. The VAS score data indicated a period or cross-over effect by which formulations administered earlier tended to have somewhat higher scores ( $\mathrm{p}$ value $<0.0001$ ). As a consequence, analysis started with the data of the first day only. The estimates of the mean VAS scores of the first day were: tablet 9.39 ( 32 children); powder 8.84 (45 children); suspension 8.26 ( 34 children) and 8.35 syrup ( 37 children); see table 2 for the CIs. The tablet scored better than the suspension even when applying a Bonferroni correction $(p=0.001$ : for correction multiply by 6 ). The other comparisons were less clear, but there was an indication that the tablet scored better than the syrup as well as the powder.

Using the data from all 4 days, estimates of mean scores per formulation were obtained across the 24 different orders of administrations, each order getting the same weight. Although no clear ranking was visible between the syrup, suspension and powder, the superiority of tablet over the other three forms was more evident than by considering the data from the first day only (table 2).

The estimate of the mean number of administrations that were fully swallowed were 1.96 (tablet), 1.58 (powder), 1.70 (suspension) and 1.67 (syrup) This number was significantly higher for the tablet than for the other formulations ( $p$ value $<0.05$ ) (table 2). The scatter-plot of the single VAS scores versus the result of the intake (data not shown) clearly illustrated that the VAS score was predictive for the result of the intake. No choking was reported.

\section{Child and parent preference}

Children and parents appeared to prefer the tablet and syrup over the suspension and the suspension over the powder ( $\mathrm{p}$ values $<0.001)$. There is also some indication $(p$ value $=0.082)$ that parents preferred the tablet to the syrup (table 3 ).

\section{DISCUSSION}

In this randomised cross-over trial, the four formulations investigated can all be considered well accepted by children between 1 and 4 years? The small $4 \mathrm{~mm}$ tablet was significantly better

Table 2 Acceptability of four different oral formulations ( $n=148$ children)

\begin{tabular}{|c|c|c|c|}
\hline & \multicolumn{2}{|l|}{ VAS score } & \multirow{2}{*}{$\begin{array}{l}\text { Result of the intake } \\
\text { All four days } \\
\text { Meant }(95 \% \mathrm{Cl})\end{array}$} \\
\hline & $\begin{array}{l}\text { First day (four different groups) } \\
\text { Mean* }(95 \% \mathrm{Cl})\end{array}$ & $\begin{array}{l}\text { All four days (cross-over design) } \\
\text { Mean* }(95 \% \mathrm{Cl})\end{array}$ & \\
\hline \multicolumn{4}{|l|}{ Numerical data } \\
\hline Tablet & 9.39 (8.85 to 9.93$), n=32$ & 9.01 (8.75 to 9.28 ) & 1.96 (1.92 to 2.00$)$ \\
\hline Powder & $8.84(8.19$ to 9.49$), n=45$ & 8.20 (7.84 to 8.56$)$ & 1.58 (1.44 to 1.71$)$ \\
\hline Suspension & 8.26 (7.47 to 9.04$), n=34$ & 7.90 (7.42 to 8.38$)$ & 1.70 (1.57 to 1.83$)$ \\
\hline \multirow[t]{2}{*}{ Syrup } & 8.35 (7.45 to 9.25$), n=37$ & 8.19 (7.73 to 8.64$)$ & $1.67(1.54$ to 1.80$)$ \\
\hline & p Value $\ddagger$ & p Value & p Value§ \\
\hline \multicolumn{4}{|l|}{ Testing for any differences } \\
\hline Tablet versus powder & $<0.001$ & 0.054 & $<0.001$ \\
\hline Tablet versus suspension & $<0.001$ & 0.001 & $<0.001$ \\
\hline Tablet versus syrup & $<0.001$ & 0.027 & $<0.001$ \\
\hline Powder versus suspension & 0.378 & 0.060 & 0.081 \\
\hline Powder versus syrup & 0.869 & 0.611 & 0.168 \\
\hline Suspension versus syrup & 0.164 & 0.302 & 0.513 \\
\hline
\end{tabular}


Table 3 Preference of four different oral formulations $(n=148$ children)

\begin{tabular}{|c|c|c|c|c|}
\hline & \multicolumn{2}{|l|}{ Child } & \multicolumn{2}{|l|}{ Parent } \\
\hline & \multicolumn{2}{|c|}{ Probability $(95 \% \mathrm{Cl})^{*}$} & \multicolumn{2}{|c|}{ Probability $(95 \% \mathrm{Cl})^{*}$} \\
\hline \multicolumn{5}{|l|}{ Numerical data } \\
\hline Tablet & \multicolumn{2}{|c|}{$0.40(0.32$ to 0.49$)$} & \multicolumn{2}{|c|}{$0.49(0.40$ to 0.58$)$} \\
\hline Powder & \multicolumn{2}{|c|}{$0.07(0.03$ to 0.11$)$} & \multicolumn{2}{|c|}{0.07 (0.03 to 0.11$)$} \\
\hline Suspension & \multicolumn{2}{|c|}{0.27 (0.19 to 0.34$)$} & \multicolumn{2}{|c|}{$0.23(0.17$ to 0.30$)$} \\
\hline \multirow[t]{2}{*}{ Syrup } & \multicolumn{2}{|c|}{$0.48(0.39$ to 0.57$)$} & \multicolumn{2}{|c|}{$0.36(0.27$ to 0.44$)$} \\
\hline & Differencet & $p$ Valuet & Differencet & $\mathrm{p}$ Valuet \\
\hline \multicolumn{5}{|l|}{ Testing for any differences } \\
\hline Tablet versus powder & 0.334 & $<0.001$ & 0.423 & $<0.001$ \\
\hline Tablet versus suspension & 0.131 & 0.046 & 0.256 & $<0.001$ \\
\hline Tablet versus syrup & -0.080 & 0.306 & 0.137 & 0.082 \\
\hline Powder versus suspension & -0.203 & $<0.001$ & -0.166 & $<0.001$ \\
\hline Powder versus syrup & -0.414 & $<0.001$ & -0.285 & $<0.001$ \\
\hline Suspension versus syrup & -0.211 & $<0.001$ & -0.256 & $<0.001$ \\
\hline
\end{tabular}

accepted than the suspension, and there was an indication that the tablet was also better accepted than the powder and syrup. The tablet was significantly more often fully swallowed than the other formulations. Children and parents preferred the tablet and syrup over the suspension, and the suspension over the powder.

Child acceptability of oral medicines has been studied for many years. ${ }^{20-22}$ Few studies however, have focussed on the acceptability of oral dosage forms as such. Ansah et $a l^{23}$ compared tablet with syrup formulations in 155 children from between birth and five years (of age) for the treatment of malaria, and Bagenda et $a^{24}$ in 129 children from between 6 months and 12 years of age in case of treatment with highly active anti-retroviral therapy (HAART). Both teams concluded that the tablet formulations resulted in better adherence. Spomer et $a l^{3}$ compared $2 \mathrm{~mm}$ uncoated placebo tablets with a sweet syrup in 60 inpatient children aged from between 6 months and 6 years of age, and concluded that the acceptability of the tablet was at least as good as that of the syrup. Despite key differences in the patient population and methodology, the results of our study are consistent with those of the aforementioned authors.

Three studies have been identified on the child acceptability of small tablets. ${ }^{3910}$ Apart from the study of Spomer et al, ${ }^{3}$ the study of Van de Vijver et $a l^{10}$ demonstrated that $2 \mathrm{~mm}$ medicated tablets were good to excellently swallowed by 16 outpatient Belgium or Dutch cystic fibrosis patients who were between 6 and 30 months of age. Thomson et al ${ }^{9}$ demonstrated that larger $3 \mathrm{~mm}$ tablets could be swallowed by 46 out of 100 inpatient British children who were 2 years old. Like the team of Spomer ${ }^{3}$ and Van de Vijver, ${ }^{10}$ we found good to excellent acceptance of the tablet, even though our tablets were of a larger size. When comparing our results with those of Thomson et $a l,{ }^{9}$ we found a better acceptance of our $4 \mathrm{~mm}$ tablets. The reason for this difference is not known, but differences in tablet characteristics, setting, cultural and behavioural attitudes may be considered. ${ }^{112526}$

This study is the first randomised cross-over trial investigating the child and parent acceptability of and preference among four oral placebo formulations in infants and preschool children. It is also the first study investigating the child acceptability of oral placebo formulations in a domiciliary rather than inpatient setting, with a double rather than single administration of each formulation, a $4 \mathrm{~mm}$, rather than a 2 or $3 \mathrm{~mm}$ tablet, and with two different measuring instruments for child acceptability.

In this study, an indication was found that the mean VAS acceptability score of the tablet was higher than that of the syrup, and that the parents preferred the tablet over the syrup. However, when parents were asked to report the child's preference, no significant difference was found between the syrup and the tablet. Results such as ours provide an argument for the fact that child and parent acceptability and preferences are different outcomes providing complementary information on the suitability of a formulation. Preferably, these outcomes are investigated in the same study.

This study has some limitations. First, the administrations were not supervised by the research team as this would bias normal family routines. Consequently, the evaluation of the child acceptability and preference relied on parental reports. This selfreporting methodology was not validated prior to the start of the study. Therefore, recruiters focused heavily on adequate verbal instructions to the method of administration and reporting.

Second, child acceptability may be influenced by taste aspects. The powder and tablet were manufactured from the same blend, so their taste was identical. However, the taste of the suspension and syrup differed due to the intrinsic nature of these dosage forms. Therefore, it cannot be excluded that any differences in the acceptability and preference among the liquid formulations were also related to taste.

Third, the recruitment was tailored to healthy domiciliary children between 1 and 4 years of age and parent with mastery of the Dutch language. Hence, the applicability of our findings to children outside this population, for example, children who are feeling ill, who are otherwise fractious or who are from a foreign ethnicity is left for future research. In view of the findings of the teams of Ansah, ${ }^{23}$ Bagenda, ${ }^{24}$ and Spomer, ${ }^{3}$ it is anticipated that our study's findings will equally hold for older children.

Fourth, chewing was not evaluated as it is common practice in The Netherlands that children may chew on immediate release tablets if they want to. Therefore, the acceptability (swallowabilty) of tablets that should be taken as a whole, for example, monolithic extended release tablets or tablets with essential taste masking, is left for future research.

Fifth, we did not systematically evaluate the parents' reasons to decline participation. However, from the voluntary reasons provided, it seemed that parents were mainly 'too busy' or having a second name suggesting a non-European ethnicity. It cannot be excluded that parents who did not participate in this study might be more reluctant to administer a particular formulation to their child than those who participated.

This study showed that the acceptability of $4 \mathrm{~mm}$ tablets is unlikely to be inferior as those of three currently employed dosage forms in infants and preschool children when aimed at a neutral taste. Thus, there is no reason to further question the acceptability of $4 \mathrm{~mm}$ immediate release tablets for children from the age of 1 year. Rather than discussing whether small tablets should be the preferred type of dosage form for the development of future paediatric medicines, pharmaceutical industries are recommended to consider the possibility of developing two essentially different dosage forms alongside each other.

\section{CONCLUSION}

Oral placebo $4 \mathrm{~mm}$ round uncoated tablets, powders, suspensions and syrups may be considered well accepted dosage forms 
in children between 1 and 4 years of age when aimed at a neutral taste. The tablets were significantly better accepted than the suspension, and there is an indication that they were also better accepted than the powder and syrup. Children and parents preferred the tablet and syrup over the suspension, and the suspension over the powder, but it was not clear whether they preferred the tablet over the syrup or otherwise. This study does not support the historic approach that medicines should normally be given to young children as an oral liquid formulation as other formulations may result in equivalent acceptability.

Contributors DAvRN: conceptualised and designed the study, coordinated the participant recruitment, coordinated the manufacture and dispensing of the placebo formulations, was responsible for the liaison with the statistician (JAF), drafted the initial manuscript and approved the final manuscript as submitted. BJdN: provided support in the design of the study towards the participant recruitment and questions in the participant diaries, was responsible for internal affairs at the preventive healthcare clinics, reviewed and revised the manuscript and approved the final manuscript as submitted. AFAMS: supervised the conceptualisation and design of the study, supervised the recruitment process and data collection, reviewed and revised the manuscript and approved the final manuscript as submitted. JAF: provided support in the design of the study towards the calculation of the sample size; he conducted the data analysis, reviewed and revised the manuscript and approved the manuscript as finally submitted. TCGE: supervised the conceptualisation and design of the study, supervised the recruitment process and data collection, reviewed and revised the manuscript and approved the final manuscript as submitted. CMAR: supervised the conceptualisation and design of the study, supervised the recruitment process and data collection, reviewed and revised the manuscript, and approved the final manuscript as submitted.

Funding The study was sponsored by a grant from the National Institute for Public Health and the Environment and the Medicines Evaluation Board in The Netherlands.

Disclaimer The opinions in this article are only those of the authors. This article is not intended to reflect the opinion of the Medicines Evaluation Board in the Netherlands (MEB) nor any of the working parties or scientific committees of the European Medicines Agency (EMA).

Competing interests Diana van Riet is coordinator/senior assessor at the department of chemical pharmaceutical assessment of the Medicines Evaluation Board in The Netherlands. She is vice chair of the European Medicines Agency's (EMAs) Quality Working Party. Alfred Schobben is a member of the MEB and expert for the EMA. Toine Egberts is also an expert for the EMA. No other conflicts of interest apply.

Ethics approval Not applicable. However, the protocol was approved by the Institutional Review Board of the Utrecht Institute for Pharmaceutical Sciences.

Provenance and peer review Not commissioned; externally peer reviewed.

Open Access This is an Open Access article distributed in accordance with the Creative Commons Attribution Non Commercial (CC BY-NC 3.0) license, which permits others to distribute, remix, adapt, build upon this work non-commercially, and license their derivative works on different terms, provided the original work is properly cited and the use is non-commercial. See: http://creativecommons.org/ licenses/by-nc/3.0/

\section{REFERENCES}

1 Nahata MC. Lack of pediatric drug formulations. Pediatrics 1999;104(3 Pt 2): 607-9.

2 Nunn T, Williams J. Formulation of medicines for children. Br J Clin Pharmacol 2005:6:674-6.

3 Spomer N, Klingmann V, Stoltenberg I, et al. Acceptance of uncoated mini-tablets in young children: results from a prospective exploratory cross-over study. Arch Dis Child 2012;97:283-6.
4 Walsh J, Bickmann D, Breitkreutz J, et al. Delivery devices for the administration of paediatric formulations: overview of current practice, challenges and recent developments. Int J Pharm. 2011:30:221-31.

5 Cohen R, de La Rocque F, Lecuyer A, et al. Study of the acceptability of antibiotic syrups, suspensions, and oral solutions prescribed to pediatric outpatients. Eur $J$ Pediatr 2009;7:851-7.

6 European Medicines Agency Committee for Medicinal Products for Human use (CHMP). Reflection paper on formulations of choice for the paediatric population. 2006. EMEA/CHMP/PEG/194810/2005.

7 World Health Organization. Report of the informal expert meeting on dosage forms of medicines for children. Geneva, Switzerland: WHO Headquarters, 2009.

8 Van Riet-Nales DA, de Jager KE, Schobben AF, et al. The availability and age-appropriateness of medicines authorized for children in The Netherlands. $\mathrm{Br} J$ Clin Pharmacol 2011;3:465-73.

9 Thomson SA, Tuleu C, Wong IC, et al. Minitablets: new modality to deliver medicines to preschool-aged children. Pediatrics 2009;2:e235-8.

10 Van de Vijver E, Desager K, Mulberg AE, et al. Treatment of infants and toddlers with cystic fibrosis-related pancreatic insufficiency and fat malabsorption with pancrelipase MT. J Pediatr Gastroenterol Nutr 2011;53:61-4.

11 European Medicines Agency Committee for Medicinal Products for Human use (CHMP). Draft Guideline on the pharmaceutical development of medicines for paediatric use R1. 2013. EMA/CHMP/QWP/805880/2012 Rev. 1.

12 Food and Drug Administration Office of Clinical Pharmacology Review. NDA 22071 Lamisil mini-tablets. 2007. http://www.fda.gov/ohrms/dockets/ac/08/briefing/ 2008-4399b1-39\%20\%28Lamisil\%20\%28terbinafine\%29\%20BPCA\%20Clin\% 20Pharm\%20Review\%20Summary\%29.pdf (accessed 5 May 2013).

13 Davitamon. Davitamon producten. 2012. http://www.davitamon.nl/baby-kind/ producten (accessed 5 May 2013)

14 de Nooijer J, Onnink M, van Assema P. Vitamin D supplementation in young children: associations with Theory of Planned Behaviour variables, descriptive norms, moral norms and habits. Public Health Nutr. 2010;13:1279-85.

15 Espelid I. Caries preventive effect of fluoride in milk, salt and tablets: a literature review. Eur Arch Paediatr Dent 2009;10:149-56.

16 Wennhall I, Matsson L, Schroder U, et al. Outcome of an oral health outreach programme for preschool children in a low socioeconomic multicultural area. Int $\mathrm{J}$ Paediatr Dent. 2008;18:84-90

17 Rijksinstituut voor Volksgezondheid en milieu (RIVM). Wat is jeugdgezondheidszorg? Nationaal kompas volksgezondheid. 2012. http://www. nationaalkompas.nl/zorg/publieke-gezondheidszorg/jeugdgezondheidszorg/ wat-is-jeugdgezondheidszorg (accessed 5 May 2013).

18 Rijksinstituut voor Volksgezondheid en milieu (RIVM). Zorgbalans. http://www. gezondheidszorgbalans.n//kwaliteit/effectiviteit-van-preventie/consultatiebureau (accessed 5 May 2013).

19 Qu RP, Zheng H. Sample size calculation for bioequivalence studies with high-order crossover designs. Control Clin Trials 2003;4:436-9.

20 Ameen VZ, Pobiner BF, Giguere GC, et al. Ranitidine (Zantac) syrup versus ranitidine effervescent tablets (Zantac) efferdose) in children: a single-center taste preference study. Paediatr Drugs 2006;4:265-70.

21 Cloyd JC, Kriel RL, Jones-Saete CM, et al. Comparison of sprinkle versus syrup formulations of valproate for bioavailability, tolerance, and preference. J Pediatr 1992;120(4 Pt 1):634-8.

22 Van Riet-Nales DA, Schobben AF, Egberts AC, et al. Pharmaceutical technology aspects of oral pediatric drugs and patient outcomes: a systematic literature review. Clin Ther 2010:5:924-38.

23 Ansah EK, Gyapong JO, Agyepong IA, et al. Improving adherence to malaria treatment for children: the use of pre-packed chloroquine tablets vs. chloroquine syrup. Trop Med Int Health. 2001;6:496-504.

24 Bagenda A, Barlow-Mosha L, Bagenda D, et al. Adherence to tablet and liquid formulations of antiretroviral medication for paediatric HIV treatment at an urban clinic in Uganda. Ann Trop Paediatr. 2011;31:235-45.

25 European Medicines Agency Committee for Medicinal Products for Human use (CHMP). Draft Guideline on the pharmaceutical development of medicines for paediatric use. 2011. EMA/CHMP/QWP/180157/2011.

26 Overgaard AB, Hojsted J, Hansen R. Patients' evaluation of shape, size and colour of solid dosage forms. Pharm World Sci 2001:5:185-8. 